\title{
VULNERAÇÃO PROGRAMÁTICA COMO CATEGORIA EXPLICATIVA DOS PROBLEMAS ÉTICOS NA ATENÇÃO PRIMÁRIA À SAÚDE
}

\author{
PROGRAMMATIC VULNERABILITY AS A CATEGORY TO EXPLAIN \\ ETHICAL PROBLEMS WITHIN PRIMARY HEALTH CARE \\ VULNERABILIDAD PROGRAMÁTICA COMO CATEGORÍA EXPLICATIVA \\ DE LOS PROBLEMAS ÉTICOS EN LA ATENCIÓN PRIMARIA A LA SALUD
}

\author{
José Roque Junges ${ }^{1}$ \\ Rosangela Barbiani ${ }^{2}$ \\ Elma Lourdes Campos Pavone Zoboli ${ }^{3}$
}

Resumo Problemas éticos da saúde pública - especialmente os atinentes à atenção primária - demandam uma abordagem específica adequada. A análise fatorial quantitativa sobre problemas éticos na atenção primária apontou gestão, longitudinalidade, prática de equipe, perfil profissional, sigilo e privacidade como pontos específicos. A etapa qualitativa posterior pesquisou exemplos e caminhos de solução, por meio de discussão focal com equipes da atenção primária de Porto Alegre e de Sapucaia do Sul, no Rio Grande do Sul. A abordagem metodológica seguida foi a Teoria Fundamentada. A análise dos resultados teve como pontos de referência as condições causais e intervenientes e as estratégias de ação diante desses problemas. A fragmentação do atendimento e a falta de protagonismo, ocasionadas pelo insuficiente planejamento e pela educação permanente, fragilizam usuários e profissionais. O refinamento desses resultados pela codificação seletiva chegou à categoria nuclear da vulneração programática como categoria explicativa da ocorrência dos problemas éticos na atenção primária.

Palavras-chave ética; saúde pública; atenção primária à saúde; vulnerabilidade social; teoria fundamentada.

\begin{abstract}
Ethical problems in public health - especially those concerning primary health care - require a specific and adequate approach. The factor analysis of quantitative data about ethical problems in primary health care pointed to management, longitudinality, team experience, professional profile, secrecy and privacy as specific topics. In the subsequent qualitative stage, we searched for examples and solutions through a focal discussion with primary health care teams in the cities of Porto Alegre and Sapucaia do Sul, in the state of Rio Grande do Sul, Brazil. The adopted methodological approach was the Grounded Theory. The analysis of the results had as reference points the causal and intervening conditions and the strategies for action when facing these problems. The fragmentation of care and the lack of prominence, caused by insufficient planning and permanent education, weaken the users and the professionals. The refinement of these results through selective codification reached the nuclear category of programmatic vulnerability as an explanatory category for the occurrence of ethical problems in primary health care.
\end{abstract}

Keywords ethics; public health; primary health care; social vulnerability; grounded theory. 


\section{Introdução}

A bioética desenvolveu ferramentas apropriadas à análise de problemas éticos da clínica mediante princípios com foco predominante no respeito pela autonomia do paciente, o qual se expressa no consentimento informado (Beauchamp e Childress, 2001). Contudo, os problemas éticos da saúde pública têm sido menos discutidos ou, quando abordados, se aplicam aos princípios usados para a bioética clínica nas questões populacionais próprias da saúde pública. É necessário, portanto, ter presente que as especificidades da clínica e da saúde pública são diferentes e trazem consequências para a abordagem ética diversa para cada âmbito ( $O^{\prime}$ Neill, 2002). A clínica foca-se na autonomia e no benefício de um indivíduo sob a responsabilidade de um profissional, e a saúde pública centra-se na distribuição justa de bens, de encargos e nas consequências dessa alocação sobre a saúde de determinada população, sob a responsabilidade de um gestor. Por isso, a aplicação dos princípios da autonomia, da beneficência, da não maleficência e da justiça se revela insuficiente para a abordagem das questões éticas da saúde pública (Upshur, 2002). Entretanto, pode-se dizer que a explicitação do princípio da justiça na obra de Beauchamp e Childress, inspirada na teoria de Rawls, pode trazer bons elementos para pensar a distribuição dos recursos na saúde pública.

Para alguns autores (Cribb, 2010; Holland, 2010), a ética da saúde pública estaria concentrada na tríade governo, população e indivíduo, uma vez que as ações dos gestores sanitários governamentais podem suscitar tensões entre os direitos e a liberdade individuais e a necessidade de proteger e de promover a saúde da população, ou seja, pode ser necessário sacrificar bens individuais para assegurar bens comunitários da saúde. Logo, a ética em saúde pública é vista como algo que trata essencialmente da ponderação dessa tensão, a fim de distribuir equitativamente entre os indivíduos e o coletivo os benefícios e os danos das decisões sanitaristas.

Nessa perspectiva, centrar a ética da saúde pública nessa ponderação mantém o foco no indivíduo, visto que se trata de justificar eticamente o sacrifício dos interesses deste ante os benefícios da população. Essa tensão não pode configurar o problema central da ética para a saúde pública em nosso contexto, embora esteja presente, tendo em vista que o desafio primordial de um sistema de saúde público atenta para como melhorar a saúde dos indivíduos com políticas públicas que favoreçam as condições de vida e de saúde da população. Por conseguinte, em conformidade com a lógica sanitarista, não existe tanto uma oposição entre os interesses dos indivíduos e os da população, mas uma complementaridade, e só é possível melhorar os índices de saúde dos indivíduos qualificando as condições de saúde de seu coletivo de pertença. 
No contexto latino-americano, surgiram propostas alternativas de bioética com os seguintes pressupostos: a bioética de intervenção (Garrafa e Porto, 2003) e a bioética de proteção (Schramm, 2003, 2006). Pondera-se que, em sociedades assimétricas e desiguais como a nossa, não pode valer a perspectiva política da igualdade e da isonomia dos indivíduos que defendem seus direitos diante do Estado - próprias de países ricos. Em situações sem vigência plena dos direitos, em que os indivíduos sofrem vulnerabilidades sociais específicas, o Estado tem o dever prestativo de intervir e de proteger a sua saúde com políticas públicas. Assim, em sociedades desiguais, trata-se de uma questão de equidade na organização do acesso aos serviços e na distribuição dos recursos da saúde. A equidade, então, contempla o foco central da bioética da saúde pública.

Embora a saúde pública não se reduza à atenção primária, os serviços desse ponto da rede organizados segundo a lógica do território representam o lugar privilegiado de comprovação da efetivação das políticas públicas sanitaristas. Por isso, o foco desloca-se do indivíduo para o coletivo, cabendo conhecer e problematizar as questões éticas que os profissionais da atenção primária enfrentam no cenário micro de sua atuação como refrações das questões éticas no nível macro da saúde pública.

O estudo realizado nos serviços de saúde comunitária do Grupo Hospitalar Conceição (GHC), empresa pública federal localizada em Porto Alegre (RS), para a validação do instrumento "Inventário de problemas éticos na atenção primária à saúde", elencou, na análise fatorial, seis conjuntos de problemas éticos com maior significância estatística: gestão; longitudinalidade; trabalho em equipe; perfil profissional; sigilo; e privacidade.

Os achados da fase quantitativa do estudo foram complementados na sequência, nos anos de 2013 a 2015, por uma fase qualitativa com grupos focais, realizados primeiramente nos mesmos serviços comunitários do GHC, e posteriormente nas unidades de atenção primária da Secretaria Municipal de Saúde (SMS) de Sapucaia do Sul (RS), município da região metropolitana de Porto Alegre. Nas sessões dos grupos focais, solicitavam-se aos profissionais exemplos concretos para os seis conjuntos de problemas éticos apontados pelo inventário validado, indicando, além do caso vivido, os caminhos de solução adotados para lidar com os problemas. O presente artigo traz a discussão dos resultados obtidos na fase qualitativa do estudo, desenvolvida em consonância com a matriz metodológica da Teoria Fundamentada.

\section{A Teoria Fundamentada como abordagem metodológica}

A pesquisa caracterizou-se como qualitativa, com a abordagem metodológica da Teoria Fundamentada, a qual tenciona construir uma teoria explicativa 
acerca de um fenômeno social, fundamentando-se nos dados empíricos - e não em outras teorias. Com isso, não se pretende apenas descrever o fenômeno estudado, mas identificar explicações para o modo como o fenômeno se expressa. Para tanto, a Teoria Fundamentada coleta dados em diferentes momentos e em universos empíricos e analisa-os simultânea e sucessivamente para refinar as categorias, por meio de diversas codificações, até chegar à categoria nuclear de construção da teoria explicativa do fenômeno. Por buscar dados empíricos que ajudem a formular a explicação pretendida, a Teoria Fundamentada não abrange um universo empírico definido de início, mas procura informantes necessários a cada codificação e adequados para clarificar determinada categoria. Esse processo - denominado como amostragem teórica - busca informantes que suscitem a descoberta de variações entre os conceitos para tornar as categorias mais densas, fornecendo dados pertinentes para desenvolver a teoria emergente (Strauss e Corbin, 2008; Charmaz, 2009).

O núcleo central metodológico da Teoria Fundamentada envolve diversas codificações - das quais, no estudo aqui apresentado, recorreu-se à proposta de Strauss e Corbin (2008), da codificação aberta, axial e seletiva. A primeira consiste na análise por frase ou por parágrafos para identificar conceitos, suas propriedades e suas dimensões, reduzindo grandes quantidades de dados transcritos a blocos conceituais menores. A segunda codificação reagrupa os conceitos que surgiram na aberta, criando, por meio de categorias e de subcategorias que associam propriedades e dimensões, eixos integradores - daí a sua denominação de axial.

O processo vai então criando um esquema de classificação e de organização das conexões emergentes que ordena os dados num paradigma. A codificação seletiva tem o objetivo de refinar a teoria, integrando as categorias ao redor de um conceito explanatório - a categoria nuclear, ou seja, o esquema teórico dominante de explicação do fenômeno, a qual é validada pela comparação com os dados brutos e o reconhecimento dos informantes. No percurso da análise, importam ainda os memorandos que acompanham a ida a campo e os diagramas que vão sendo desenhados nas diversas codificações (Strauss e Corbin, 2008).

O campo empírico concreto da pesquisa englobou os serviços de atenção primária do GHC de Porto Alegre e da SMS de Sapucaia do Sul. Os primeiros, por integrarem um serviço-escola do Ministério da Saúde, têm equipes antigas experientes e contam com uma variedade de profissionais da saúde. Os segundos, de formação mais recente, compõem uma organizada rede de atenção primária. A pesquisa foi aprovada pelo Comitê de Ética em Pesquisa (CEP) da Universidade do Vale do Rio dos Sinos (Unisinos) pela resolução n. 031/2013, e os participantes, por sua vez, assinaram o termo de consentimento. 
Na primeira etapa da coleta dos dados qualitativos, incluíram-se seis equipes do GHC, indicadas pela coordenação dentre as 12 que haviam participado da fase quantitativa do estudo. O grupo de discussão focal dessas seis equipes incluiu dez participantes cada um, escolhidos por representação profissional entre os quase trinta integrantes. Posteriormente, incorporaram-se quatro equipes indicadas pela SMS de Sapucaia do Sul, tendo 12 participantes cada uma, correspondendo a todos os integrantes da equipe. Assim, somando-se, foram dez equipes de atenção primária que compuseram o universo empírico e o material de pesquisa para a codificação aberta. Essa primeira fase da discussão focal versou sobre exemplos concretos de problemas éticos da atenção primária e seus caminhos de solução.

Da análise aberta dos dados qualitativos dos primeiros grupos focais, emergiram conceitos relativos aos seis conjuntos de problemas éticos apontados pelo inventário validado, ao mesmo tempo que já foram se constituindo algumas subcategorias de integração associadas por suas propriedades e por suas dimensões. Esse material codificado foi levado numa nova incursão no campo para mais três equipes da SMS de Sapucaia do Sul, tendo, cada uma, 12 integrantes, que não haviam participado dos primeiros grupos focais, escolhidas intencionalmente por sua experiência e boa integração, de modo a se aprofundarem os achados da fase anterior. O material transcrito da segunda rodada de discussão focal feita com as três equipes sapucaienses foi submetido à codificação axial para classificar e organizar as subcategorias, por meio de suas conexões num modelo explicativo.

Finalmente, o modelo foi confrontado em uma terceira discussão focal, da qual participou uma das equipes de Sapucaia do Sul da fase anterior, escolhida intencionalmente pela competência prática e pela capacidade reflexiva, o que se demonstrou durante a participação na segunda rodada de grupos focais. $\mathrm{O}$ material coletado nessa rodada serviu para a codificação seletiva. Para refinar a teoria que ia emergindo, os resultados da codificação seletiva foram completados pelo confronto com os dados brutos da transcrição e pelo reconhecimento individual de profissionais. Seguindo-se as sucessivas codificações da Teoria Fundamentada, pôde-se alcançar uma categoria explicativa para o fenômeno dos problemas éticos na prática da atenção primária.

\section{Resultados das codificações}

Na Teoria Fundamentada, a codificação dos conceitos, das subcategorias e das categorias do fenômeno estudado (problemas éticos) no seu contexto (serviços de atenção primária à saúde) permite identificar, segundo o modelo preconizado por Strauss e Corbin (2008), os seguintes elementos definidores do fenômeno: as condições causais; as condições intervenientes; as estraté- 
gias de ação/intervenção; e as consequências. A apresentação dos resultados seguiu esse esquema para cada conjunto dos problemas éticos. Ao final, evidenciou-se e discutiu-se a categoria nuclear explicativa dos problemas éticos na atenção primária, que resultou do processo dialético investigativoanalítico empreendido na pesquisa. As referências às transcrições dos diversos grupos focais do GHC tiveram a numeração de 1 a 6 ( $\mathrm{GHCl}$...), e aquelas da SMS, de 1 a 8 (SMS1...).

\section{Codificação aberta (condições causais, condições intervenientes, estratégias de ação/intervenção)}

Os profissionais participantes dos grupos focais ilustraram, com exemplos concretos dos problemas éticos, dificuldades e caminhos de solução. O material subsidiou a codificação aberta. Quanto à gestão, a condição causal mais apontada foi o não funcionamento da rede de atenção, o que se explicitou na dificuldade de conseguir um especialista: "Encaminhamento para outros serviços não depende de nós, depende do gestor (...)” (médica GHCl), em razão da regulação complicada das consultas eletivas por meio do sistema de Gestão e Regulação Assistencial e Financeira de Saúde (AGHOS) da Secretaria Estadual de Saúde, que distribui as vagas "por cotas para as áreas, não importando onde a pessoa mora" (administrativo GHC2); assim, “a via de regulação do Estado é complicada" (médica SMS1) e gera "dificuldade de acesso a especialidades, de fazer exames" (técnica de enfermagem SMS4). Tal panorama acarreta a descontinuidade do tratamento devido à longa espera por um exame: “a pessoa precisa de um especialista e o município não oferece, vai para a fila do Estado, que libera uma consulta mensal daquele especialista" (médica SMSl).

Por um lado, a condição interveniente contempla a falta de contrarreferência, em que "o usuário é encaminhado, mas ele não retorna com contrarreferência" (dentista GHC6), o que obriga o profissional a basear-se no relato do "paciente que conta o que aconteceu" (enfermeira2 SMS2) "do jeito dele" (médica SMS2). Por outro lado, há a desvalorização, pelos profissionais do hospital, do diagnóstico e da terapêutica, feitos na atenção primária: “eles acham que o posto não é habilitado para mandar uma pessoa" (agente comunitária SMS3); a "técnica do hospital disse que eu não sabia verificar a pressão, e a gente encaminhou justamente porque a pressão estava alta, e gestante com pressão alta é gravidez de risco" (técnica de enfermagem SMS3).

As estratégias de ação das equipes diante dessas condições causais e intervenientes abrangem a busca de caminhos alternativos, como procurar o setor privado - "se é um paciente que tem condições, pagar a consulta particular, mas eticamente a gente não pode indicar o serviço para o paciente" (médica 
GHCl) - e a intervenção especializada, sem preparo, porque "vai ter um benefício para o paciente; se não fizer, ele vai ficar simplesmente esperando na fila" (médica GHCl). A atenção ao usuário gera pressão para o profissional dar uma resposta: "a gente tem responsabilidade, como atenção básica" (enfermeira GHC3), apelando até para contatos pessoais: "eu tive que falar com o diretor do hospital para pedir uma vaga" (médica GHC3); ou "a gente tenta ir pelas curvas onde dá uma brechinha, entrando em contato com a secretaria (...) é o jeitinho brasileiro" (médica SMS1), e "a possibilidade de formar conselho local de saúde para chegar na gestão, mas a coisa é muito fechada" (enfermeira SMS4). Outra estratégia é orientar o paciente a "ir para a defensoria pública, entrar com um processo judicial contra a instituição, que tem que dar conta desses pacientes que ficam desassistidos" (enfermeira GHC6), ou ainda denunciar à imprensa.

No que diz respeito à longitudinalidade - entendida como o acompanhamento ao longo da vida das pessoas com condições crônicas de saúde -, a condição causal desvela a dificuldade de conjugar beneficência e autonomia do usuário: "até onde podes intervir, até onde não, respeitando a vontade dele, até onde ir como equipe de saúde" (médica GHCl). No entanto, a questão amplia-se para a responsabilidade quanto à saúde pessoal: "as pessoas estão se eximindo sempre mais de sua responsabilidade, colocando no posto e nos profissionais uma parte da responsabilidade" (enfermeiro GHC4). Entende-se que isso ocorre porque "tem essa resistência de compreensão da doença, não querem saber, querem viver a vida" (técnica bucal GHC4). Ademais, o profissional reconhece seu papel de "conscientizar (acerca) da importância de vir ao posto, trabalhar mais a autonomia dos usuários" (auxiliar saúde bucal SMS4).

A condição interveniente abarcou a identificação da atenção primária com o modelo biomédico, que se manifesta pela dificuldade de agendamento de consultas em grupo, pois "as pessoas têm dificuldade" (dentista GHC2), preferindo o sistema da demanda, "funcionando com fichas e fila de manhã" (psicóloga GHC2). Identifica-se ainda a utilização do serviço de atenção primária com pronto atendimento, já que "os usuários têm dificuldade para entender que a estratégia não é pronto atendimento. É uma sequência, não uma foto do paciente, é um acompanhamento periódico" (médica SMS1); "a gente sempre fala que não é pronto atendimento, que vai quando está doente" (técnica de enfermagem SMS3). Assim ocorre na busca por uma consulta para sanar sintomas de evento agudo, para receber a medicação: "eles vêm realmente quando está sintomático, querem resolver num dia" (médica SMS1); “a pessoa toma a medicação, fica boa, nunca mais volta" (agente comunitária SMS1). Dentre as estratégias de ação, destaca-se a ampliação da clínica na atenção primária:

trabalhar o todo daquela pessoa, no hospital importa aquele diagnóstico, aqui importa onde a pessoa vive, tem lixo na casa, tem tratamento de esgoto, tem ca- 
chorro, a criança e avó vive (sic) junto, é um contexto que envolve muitas coisas complexas, é um desafio essa relação de cuidado (enfermeira2 SMS2).

Diante da pouca eficácia dos grupos organizados por patologias crônicas, que "só têm efeito se forem de acordo com a realidade da comunidade; do contrário, partem da necessidade do profissional, que não é a do usuário" (enfermeira SMS3), surgem soluções alternativas:

a gente tem um grupo de caminhada que está firme e forte, o grupo de artesanato para fazer tricô, crochê, fuxico, pequenas atividades manuais, grupo de terapia para quem tem tratamento psiquiátrico, pois pobre não tem solução, vai fazer caminhada (médica SMS1).

Desse modo, “o grupo de caminhada é, na verdade, de educação em saúde" (enfermeira SMS3), e o próprio "grupo dos hipertensos e diabéticos virou grupo de atividade física" (enfermeira SMS4). Além disso, "também temos rodas de terapia comunitária, terapia em grupo" (agente comunitária SMS4). Tais estratégias sustentam-se no reconhecimento da necessidade de atenção, por parte do usuário, e do papel profissional de não abandoná-lo: "não desistir, porque chega a hora que a gente está de saco cheio (sic), fica rançoso, não quer mais ouvir falar do paciente, mas esse paciente merece continuar tendo toda a nossa atenção" (enfermeira SMS4). Apesar disso, há culpabilização dos usuários: "fruta e verdura é cara (sic), mas chega a mãe e diz: 'doutora, ele não come comida, só come porcaria'; mas é a mãe que compra as porcarias no mercado" (médica SMS1). Já o agente administrativo constata: “vejo criança no colo, esperando consulta, com sete ou oito meses, com latinha de refrigerante na mão, em vez de uma banana ou maçã" (agente administrativo SMS1).

Para as iniciativas dessas estratégias de ação, as equipes buscam a contribuição de parceiros nas redes de apoio - muitas vezes, sem obter a resposta desejada: a "associação de bairro está fechada, está se reerguendo" (médica SMS1). Também se reconhece a necessidade de desenvolver ações intersetoriais de longo prazo: "tem coisas que a saúde não dá conta, a gente precisa de outros setores" (enfermeira SMS3), porque "você age no curto período, não mexendo na estrutura dos determinantes que vão produzindo a saúde $\mathrm{e}$ a doença, com o passar do tempo" (enfermeira GHC5).

A condição causal para os problemas éticos pertinentes à prática em equipe e ao perfil profissional enfatizou, por um lado, a formação profissional, uma vez que "a universidade não prepara para trabalhar em equipe" (dentista $\mathrm{GHCl}$ ), e por outro, a atuação profissional, "a que não se pode olhar apenas para o núcleo, mas ter uma abertura para o campo com todas as questões que isso envolve e respeitar a opinião do outro" (médica GHCl), tendo em vista que "para trabalhar em equipe, tem que (sic) lidar com questões multiprofis- 
sionais (dentista GHC5), e “o campo é de todos, não é de ninguém" (enfermeira GHC6). Por isso, os profissionais concordam que "o teu trabalho só vai ser efetivo se estiver inserido num contexto de equipe" (enfermeira GHC5), e "a gente tem que tentar conversar e esclarecer, porque fora podemos não ser amigas, mas temos que ser colegas de trabalho" (médica SMS1).

A condição causal para a falta de perfil ocorre "porque o profissional não está acostumado com a dinâmica da atenção primária" (médica $\mathrm{GHCl}$ ), porque "faz aquele atendimento básico, não se envolvendo" (auxiliar GHC2), "tem dificuldade em fazer vínculo" (enfermeira GHC3) e em "inserir-se nos espaços comunitários" (assistente social GHC3), com "um perfil julgador, que não consegue orientar, acolher e ajudar" (coordenadora GHC4). Na atenção primária, "você não trabalha com peças cirúrgicas nem imagens radiológicas, mas com pessoas onde ( $\mathrm{sic}$ ) não existe distanciamento" (médico GHC 5), em que "não serve gente chique, que trabalha de salto" (agente comunitária SMS1), e "não consegue fazer o acolhimento" (enfermeira2 SMS2) ou "sentar, conversar, ver o paciente, escutar o que está falando" (técnica de enfermagem SMS3).

Condições intervenientes apontaram para o favorecimento de certos usuários, provocando conflitos por "uma liderança negativa, que desestrutura a equipe" (médico GHC4), ou divergir no que tange ao tratamento dado ao usuário, ao se "consultar com outro médico que, por alguma razão, troca a medicação e a pessoa fica insegura; se existe divergência, melhor manter e conversar com o colega" (auxiliar de enfermagem GHC6) e "chamar outro profissional" (agente comunitária SMS3).

As ações/intervenções para o enfrentamento dos problemas mencionados englobam reuniões de equipe para "aprender a conhecer e a respeitar o outro" (médica GHCl), para "conversar e falar a mesma língua" (técnica de saúde bucal GHCl), "tentando compor e não se sobrepor" (dentista GHC6) por meio da pactuação de "um plano terapêutico para os pacientes" (auxiliar de enfermagem GHC6).

As condições causais e intervenientes, quanto ao sigilo e à privacidade, diferiram entre as equipes do GHC e da SMS de Sapucaia do Sul. Para as primeiras, a condição causal do problema não sintetiza prática dos profissionais que precisam respeitar o sigilo e a privacidade, porque isso sempre é pactuado nas reuniões, mas "a questão do armazenamento dos prontuários de nossos pacientes, que compromete o sigilo dos pacientes de forma contínua" (gestor $\mathrm{GHCl}$ ). A condição interveniente do problema trata da exposição e da facilidade de acesso aos prontuários, devido à sua localização. A estratégia de solução é "informatizar" (técnica de enfermagem GHCl), e "a tecnologia já existe para isso, mas a gestão sempre é deixada de lado" (gestor GHCl).

Para as equipes de Sapucaia do Sul, a condição causal do problema - objeto de permanente preocupação nas reuniões - envolve a presença das agentes comunitárias de saúde no acompanhamento dos usuários. A proximidade e 
o vínculo dessas profissionais representam uma condição interveniente que pode atrapalhar a privacidade das informações: “as gurias, por serem do bairro, os usuários se dirigem a elas para saber qual a doença do vizinho, e elas sabem que isso é sigiloso" (médica SMS1). A estratégia de "solução foi discutir, trazer para a reunião para ser solucionado, ou discutir separadamente com cada agente, não trazendo para a reunião" (médica SMS2). Por isso, "para que as agentes fizessem o acolhimento, a gente discutiu muito sobre a questão do sigilo" (médica SMS3).

\section{Codificação axial: emergência dos eixos estruturais básicos}

O quadro conjuntural (condições e reações) dos problemas éticos na atenção primária delineou eixos de consequências estruturais no âmbito do próprio sistema de saúde. A codificação axial descortinou categorias, subcategorias e conceitos mais sintéticos, a partir da codificação aberta. Assim, a síntese do complexo categorial construído com base na análise axial pode ser representada pela Figura 1, sobre os eixos estruturais dos problemas éticos na atenção primária:

\section{Figura 1}

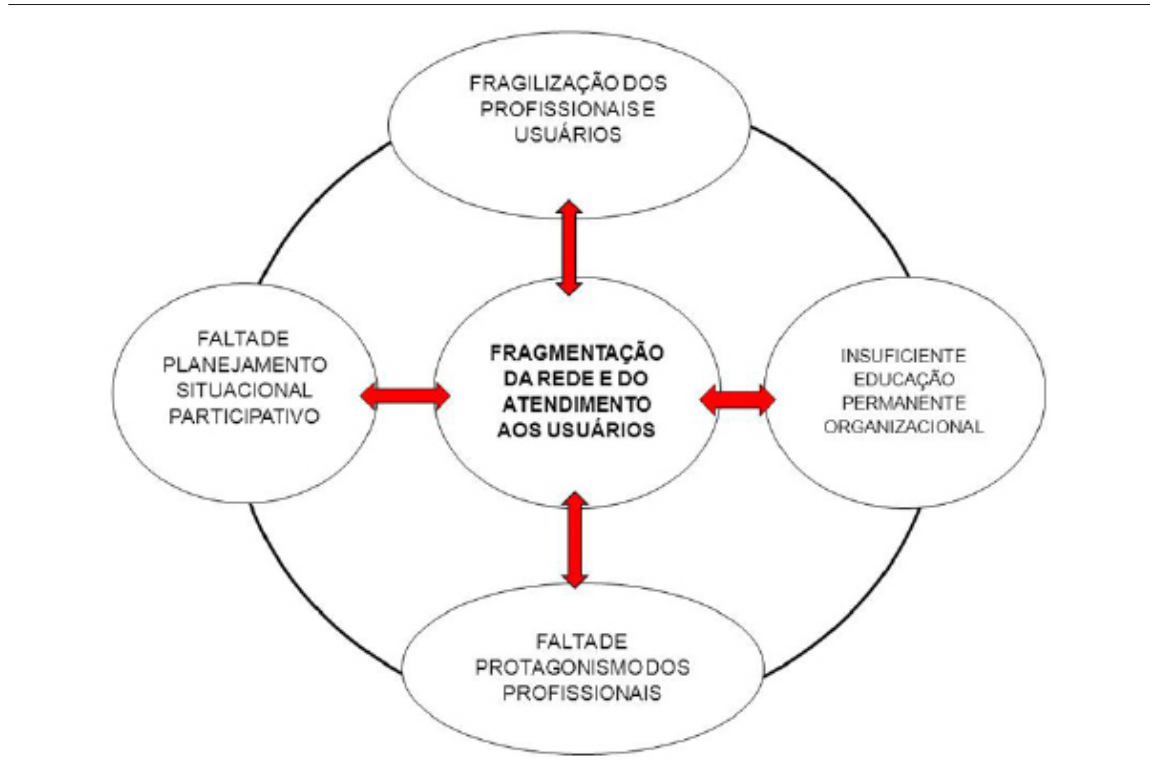

Fonte: Os autores.

Em seu conjunto, os elementos elencados têm em comum determinada narrativa de impossibilidades, cuja análise axial procurou enunciá-la além de sua expressão fenomênica. 
O funcionamento inadequado da rede de atenção foi apontado com frequência e por diversos motivos, "pois não adianta ter pontos da rede se não tem trânsito na rede" (enfermeiro SMS5); ou, ainda, a "rede está travada" (dentista SMS6), provocando a descontinuidade no tratamento pela falta de contrarreferência, em que "as coisas não chegam para a atenção básica" (residente SMS6), e para saber o que foi feito no serviço de referência, “o paciente nos conta o que aconteceu na consulta, do jeito dele" (enfermeira SMS6). Esse fato sinaliza uma desvalorização da atenção primária por parte de outros profissionais, que "dizem que só bateram lá porque o postinho não funciona" (dentista SMS6). A constatação também causa frustração, porque "é mais fácil se adequar do que eles darem algum retorno" (dentista SMS6).

As consequências detectadas da fragmentação e do não protagonismo se devem à falta de planejamento situacional participativo, tanto da gestão quanto da atenção, considerando-se que, para os profissionais, planejamento significa organização da demanda, como "saber quantas gestantes não vieram no mês, quem não veio vacinar esse mês" (enfermeiro SMS5). O planejamento é entendido como a monitorização e a vigilância da demanda: “a gente tem pouco tempo para sentar e planejar, não tem o costume de fazer um planejamento anual" (enfermeiro SMS5). "A gente planeja o que é importante naquele mês" (médico SMS6). Por isso, "a gente foca só na demanda do dia, a questão de planejar e avaliar metas não se estabelece, não se enxerga o nosso processo de trabalho" (médica SMS5). “O que incomoda é a falta de estrutura para um planejamento efetivo, porque não há dados informatizados, um prontuário eletrônico" (médica SMS6).

O planejamento é também compreendido como um dispositivo grupal para potencializar a participação e a reflexão dos profissionais no sentido de superar a padronização mecânica do atendimento, de tomar consciência da cultura organizacional e da distribuição do poder vigentes na equipe e de construir projetos que possam ser assumidos coletivamente como compromissos numa gestão colegiada. Existe, além disso, uma insuficiente educação permanente organizacional da equipe, com reuniões geralmente dedicadas à distribuição de tarefas e à solução de problemas pontuais, decorrentes da pressão do tempo. A educação permanente

surge mais transversal nas reuniões da equipe, mais pontual, como a campanha da vacinação, porque tem muitas pautas administrativas para focar, e as duas horas de reunião ficam apertadas, por isso, desorganizou a educação permanente mais formal, é mais por núcleo profissional (enfermeiro SMS5).

Em vista disso, a educação permanente não pode ser reduzida à educação continuada, identificando-se com a simples atualização de conhecimentos e o aprendizado de novas técnicas por um modelo de transmissão. Ao contrário, 
configura o aprendizado no cotidiano da atenção pela problematização das práticas de trabalho, provocando estranhamento crítico quanto ao pensar e ao agir no contexto profissional, na busca de alternativas para o atendimento e para a organização do serviço (Brasil 2009). Isso tudo acarreta a fragilização tanto de usuários quanto de profissionais - pela fragmentação do atendimento e pelo insuficiente protagonismo profissional na deliberação e na condução do atendimento, ao se inferir que "não tem empoderamento para mudar isso, fazer o sistema andar não depende de nós" (residente SMS6), e “às vezes, a gente se obriga a passar pelo informal para resolver o problema" (dentista SMS6).

\section{Codificação seletiva: emergência da categoria nuclear explicativa do fenômeno}

Da apreciação das categorias averiguadas na fase axial, em nova incursão de campo, os participantes de uma equipe aprofundaram os eixos estruturais básicos em duas discussões focais (SMS7 e SMS8), nas quais descreveram e analisaram longamente o acompanhamento longitudinal de uma usuária em situação de extrema vulnerabilidade social, com comorbidades crônicas (diabetes e hipertensão), o que dificultava o cuidado e tornava estressante a relação com os profissionais. Entre a primeira e a segunda reuniões de discussão focal, a usuária em questão acabou passando por amputações nas mãos e nas pernas e por um enfarte do miocárdio, o que marcou muito os profissionais e fez com que o foco no caso persistisse. Os profissionais descreveram-na como: "socialmente falando, ela mora num lugar bem precário, não tem rede de apoio, não tem família, vive só" (enfermeira SMS8), e notaram os determinantes sociais de seu processo de saúde e de doença.

Ela não tem uma patologia psiquiátrica, ela tem as contingências ruins da vida, ela tem uma vida ruim, a sua patologia é a vida ruim. É uma pobreza, uma sujeira, uma pobreza de espírito, uma sujeira de casa, é falta de recursos, é falta de ferramentas de vida para sair disso, talvez, falta de resiliência (médica SMS8).

A fragilização reparada pelos profissionais acabou comprometendo até mesmo o sigilo e a privacidade quanto à vida da usuária, como relatou a médica: “Os meus irmãos moram ali e me dizem: 'eu passei por aquela tua paciente da cadeira de rodas', porque todo mundo sabe e conhece, porque ela é um assunto de vida, quando eu passo ali, digo: essa é minha paciente" (médica SMS8). A fragilização, para os profissionais, se visibiliza na sua própria necessidade de chamar a atenção: "ela tem uma carência, ela quer ser cuidada, mas ela não quer se cuidar (...) - 'eu não quero fazer nada por mim, é (sic) que têm que fazer" (agente comunitária, SMS7). A necessidade de atenção exige "uma intimidade que não existe, ela demanda muito, ela força a gente" (médica SMS7), 
o que viabiliza que ela defina "qual cuidado quer, como fazer os curativos" (médica SMS7) - os quais, quando estão sujos, provocam sua reação: "não me xinga, não me xinga" (enfermeira SMS8). Essa proximidade da usuária com a equipe ultrapassa a questão da saúde, ao chegar ao ponto de "ela dizer: 'olha aquelas batatas para mim no fogão'” (agente comunitária SMS7).

Ao mesmo tempo, a situação de extrema fragilização da usuária sentida pela equipe se confirmou na constatação da médica: “ela está morrendo aos poucos, perdeu uma perna, um pé, a ponta dos dedos da mão, e agora, enfartou" (médica SMS8); ver a situação “dá pena mesmo" (enfermeira SMS8) ou desperta "um sentido de tolerância para com ela, aquilo te comove, mas tu não podes deixar de fazer aquilo que tem de fazer, não pode mudar de opinião, tem que continuar" (técnica SMS8).

A ampliação da clínica para a inclusão do contexto maior da determinação social da saúde da usuária, conjugado ao cotidiano das práticas singulares de cuidado, estressa a equipe e promove o revezamento no cuidado: "quando um começa a ficar muito saturado, a gente reveza" (médica SMS7); "hoje eu não estou bem para ir à casa dela. Você se angustia com ela agora no pós-enfarto, não está tomando a medicação, porque ela não quer" (técnica SMS8); "porque é emocionalmente desgastante" (enfermeira SMS8); "tem que deixar ela por último, porque vai demandar mais tempo, mais energia, vai pronto para mais do que pelo curativo, porque vai estar tudo ao contrário" (médica SMS8).

A persistente falta de melhora das condições de saúde a despeito dos esforços constantes da equipe para o cuidado consequentemente induz a médica a culpá-la: "Ela não adere à mudança de estilo de vida para conseguir controlar a diabete (sic), sempre encontra subterfúgios para desviar, nunca a culpa é dela" (médica SMS8). A limitação sentida pela equipe para o enfrentamento da situação de vulnerabilidade da usuária acaba fragilizando os profissionais:

eu passei uma prescrição, a parte da paciente é cumprir isso, a gente se depara com alguém que não faz isso, e ainda assim ter que manter o cuidado e investir naquela pessoa é muito difícil, é a questão do nosso ego, formado na lógica de que eu detenho o conhecimento e você, paciente, assimila meu conhecimento. Esse é o nosso processo de transferência. Ela mobiliza muito, saber que ela não vai fazer o que estou dizendo, a gente viver brigando, ter que buscar novas maneiras de ajudar (médica SMS8).

Nessa transferência, a médica avalia que há certa inversão de papéis na relação com a usuária: "ela usa a gente para o que ela quer e não quer, a gente tem aceitado essa posição dela, a forma de a gente fazer o cuidado dela" (médica SMS8). Outrossim, não somente os desafios diários do cuidado concreto da usuária fragilizam os profissionais, mas o fato de eles não conseguirem programar o cuidado, que se restringe às visitas e ao acompanhamento 
“da pressão depois do enfarto" (técnica SMS8), “da glicemia, é muito difícil (médica SMS8).

A falta de programação dificulta a prevenção e impossibilita a promoção da saúde da usuária, no caso. Além de não conseguir programar o cuidado, a equipe não conta com a rede para a ajuda de um psicólogo: "nós temos matriciamento de uma equipe de apoio de saúde mental, mas não tem um psicólogo que acompanhe nossos pacientes" (médica SMS8). Para a equipe, a ajuda externa de forma matricial se mostra insuficiente: "porque a minha visão de uma pessoa que vem matriciar, ela vem para ajudar num caso particular" (enfermeira SMS8).

Os profissionais se dão conta de que a questão da saúde não se restringe ao biológico e reconhecem, simultaneamente, as limitações que têm para o cuidado integral: "não é só o problema de diabetes ou o problema vascular, é toda a vida dela, com suas necessidades, mas isso é muito complicado, porque é muito complexo, e a gente não vai dar conta" (enfermeira SMS8). O reconhecimento que se processou denota a fragilização decorrente da complexidade inerente à lógica programática e de ampliação da clínica que caracteriza o funcionamento da atenção primária. Por sua vez, a visão de rede está circunscrita às especialidades e à esfera intrainstitucional, e a equipe não refere articulação com a rede de assistência social - que, nesse caso, poderia potencializar o trabalho da saúde.

Ao descrever as condições de saúde da usuária, os profissionais ressaltaram a importância reconhecida da situação de extrema vulnerabilidade social em que ela vive: "ela tem as contingências ruins da vida, ela tem uma vida ruim, a sua patologia é a vida ruim". Em outras palavras, os profissionais reconhecem que os determinantes sociais colocam-na em condições que a vulneram, configurando a sua patologia e limitando as possibilidades de intervenção da equipe.

Há, portanto, duas ordens de determinação dos problemas éticos, em constante movimento e interação: a primeira, relativa aos eixos estruturais do sistema de saúde; e a segunda, associada às condições de saúde e de vida dos usuários. Nessa interseção, configurou-se a categoria nuclear explicativa do fenômeno estudado: vulneração programática, que se representa em seu complexo de determinações na Figura 2. 


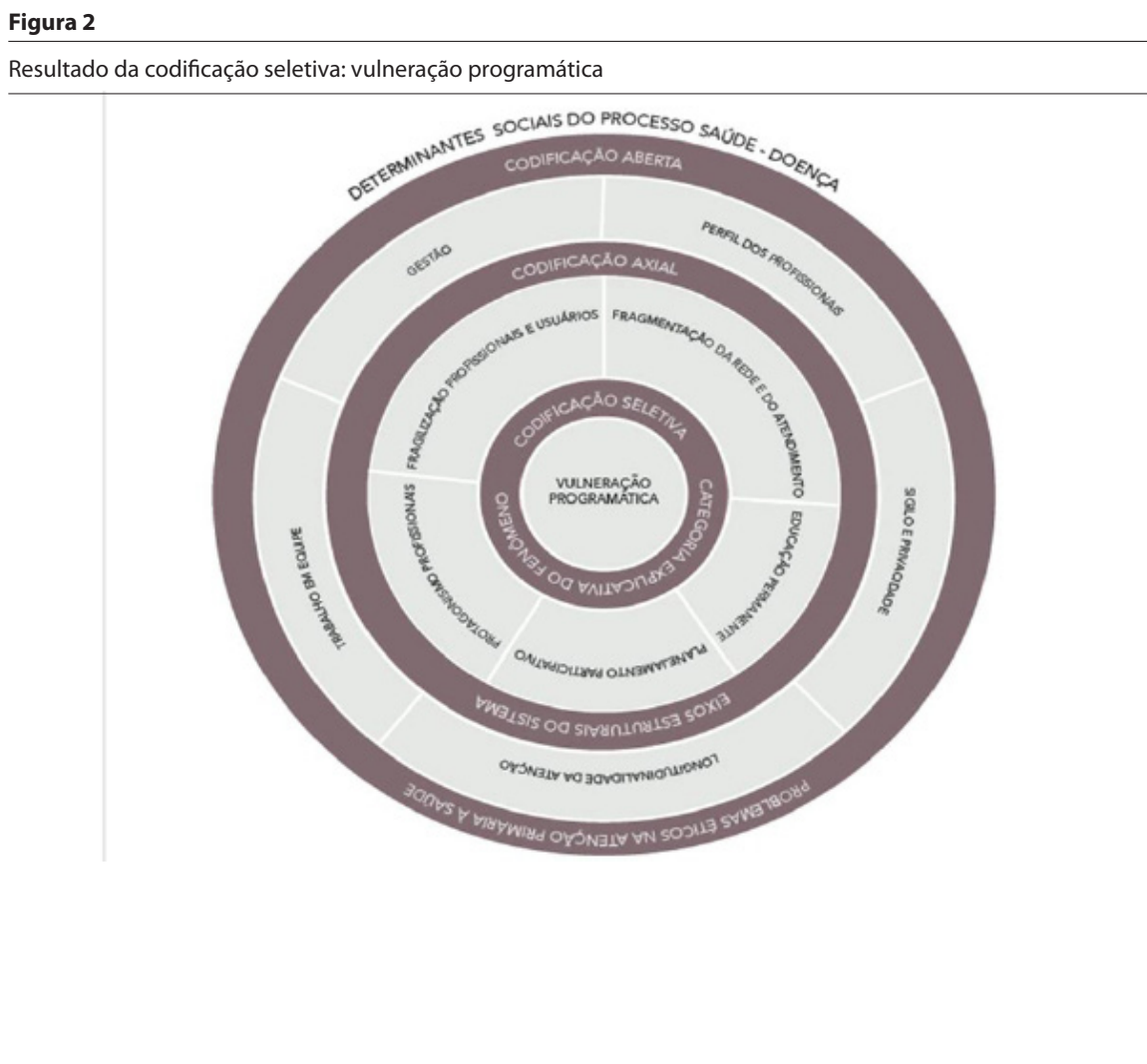

Fonte: Os autores.

\section{A vulneração programática como categoria nuclear}

As categorias construídas na fase de codificação seletiva evidenciaram a fragilização dos usuários e consequentemente dos próprios profissionais, o que decorre principalmente do funcionamento insuficiente e fragmentado da rede de saúde. Esse resultado é análogo à categoria da vulnerabilidade programática, entendida como uma fragilização do usuário que acorre a um serviço, devido ao modo como está organizado e programado o atendimento (Ayres et al., 2003).

Após o refinamento dessa categoria por meio do confronto com dados e outros informantes correspondentes à fase de codificação seletiva, chegouse à denominação de vulneração programática numa coerência lógica com o conceito de vulneração social. Logo, a vulnerabilidade é uma característica essencial do ser humano, por sua fragilidade em relação ao ambiente, por estar em permanente inacabamento e em reconfiguração de suas dimensões biológica, psíquica e mental para a constituição de sua unidade pessoal. Conscientes dessa vulnerabilidade radical, todas as sociedades humanas criaram 
historicamente estruturas culturais e sociais de cuidado à fragilidade natural, como a família, o clã, a comunidade.

Nos tempos modernos, em virtude das transformações políticas e econômicas, surgiu uma vulnerabilidade que não está atrelada à fragilidade natural, mas ao estatuto de cidadania do ser humano para o qual o Estado teve que tomar medidas. Por isso, Kottow $(2003,2004)$ distingue entre vulnerabilidade e suscetibilidade à vulnerabilidade, ou melhor, a vulneração. A primeira é a vulnerabilidade substancial, que frutifica da fragilidade natural, de cunho individual, necessitada de cuidado. A segunda abarca a suscetibilidade a vulnerar-se, que não é natural, mas criada pelas condições sociais e estruturais nas quais vive esse indivíduo. A usuária em questão, no caso focalizado nos grupos, além de sua vulnerabilidade singular para se adoentar, sofre da vulneração social decorrente de suas condições de vida e de sua biografia, agudizando o seu quadro patológico.

Os profissionais perceberam a extrema fragilidade da usuária pela situação social de vulneração na qual ela vive, e sentiam-se impotentes diante desse quadro. A condição de vulneração social dificulta o acesso da usuária à rede de serviços - tão necessários ao seu quadro patológico -, o que desencadeia estresse e desgaste dos profissionais, que diante do sofrimento psíquico moral da convivência com as limitações para o cuidado acabam automatizando-o, uma vez que já não é mais possível vislumbrar o que fazer para cuidar, com acolhimento e integralidade, da usuária. Então a vulnerabilidade social dos usuários dos serviços junta-se à vulnerabilidade programática da rede de saúde, o que causa a vulneração de quem está envolvido no cuidado (usuários e profissionais).

A vulneração programática aparece como base para a teoria explicativa da ocorrência de problemas éticos na atenção primária, com o território como expressão da determinação macrossocial do processo saúde/doença. Além da vulneração ocasionada pelas condições sociais em que a usuária vive, há um acréscimo de vulneração - chamada de programática - ao receber o atendimento, devido à fragmentação no acesso às redes de atenção à saúde, provocando descontinuidade no tratamento e falta de motivação para o cuidado. Portanto, a fragmentação e a descontinuidade resumem fatores de vulneração programática da usuária, embora os dados evidenciem que existe simultaneamente a vulneração programática dos próprios profissionais, causada pela sensação de fragilização - que deriva da impotência para solucionar os casos dos usuários e da consequente falta de protagonismo no atendimento. 


\section{Considerações finais}

A incidência dos determinantes sociais no processo saúde/doença contempla um dos pressupostos da saúde coletiva e uma constante da prática dos profissionais da atenção primária, que consistem na base de muitos problemas éticos que perpassam pelo seu dia a dia. Então, eles se dão conta da necessidade de considerarem as condições de vulneração social que configuram os quadros patológicos e determinam os caminhos do cuidado longitudinal de seus usuários. Todavia, têm menos consciência da vulneração acrescida à social - que é a programática, ocasionada pelos percalços que o usuário sofre para ter acesso aos serviços da rede e também pelo modo como acontece o próprio atendimento. Tais dificuldades vulneram programaticamente o usuário porque descontinuam e desmotivam o tratamento e o cuidado, que já sofre impossibilidades pela sua condição social. A impotência diante desse quadro fragiliza também programaticamente os próprios profissionais, impossibilitados de acessar os meios necessários para atender satisfatoriamente às necessidades dos usuários, o que provoca estresse e angústia.

Em suma, a vulneração programática sintetiza a categoria explicativa dos problemas éticos que se expressam fenomenicamente como questões de gestão, de longitudinalidade, de prática em equipe, de perfil para atenção primária ou de sigilo e privacidade, mas cuja compreensão se adensa quando se examinam as condições causais e intervenientes desses problemas e suas estratégias de solução. Assim, fica claro que a substância ética dos problemas reside no fato de vulnerarem os usuários e os profissionais pela interdependência entre o sistema de saúde e o contexto social em que ele se insere.

\section{Colaboradores}

José Roque Junges foi o responsável pelo projeto de pesquisa em sua construção e desenvolvimento, fez a coleta e a análise dos dados e escreveu o artigo. Rosangela Barbiani ajudou na fase final da pesquisa para o refinamento da categoria nuclear, para a construção das figuras e a revisão final do texto. Elma Lourdes Campos Pavone Zoboli participou na elaboração do projeto e na análise dos dados. 
Resumen Los problemas éticos de la salud pública - especialmente los relativos a la atención primaria - demandan un abordaje específico adecuado. El análisis factorial cuantitativo sobre problemas éticos en la atención primaria indicó gestión, longitudinalidad, práctica de equipo, perfil profesional, sigilo y privacidad, como puntos específicos. La etapa cualitativa posterior analizó ejemplos y caminos de solución, por medio de la discusión focalizada con equipos de la atención primaria de Porto Alegre y Sapucaia do Sul, en Rio Grande do Sul. Se utilizó la Teoría Fundamentada como abordaje metodológico. El análisis de los resultados tuvo como puntos de referencia las condiciones causales e implicadas, y las estrategias de acción frente a estos problemas. La fragmentación de la atención y la falta de protagonismo, ocasionadas por la insuficiente planificación y la educación permanente, fragilizan a usuarios y profesionales. El refinamiento de estos resultados por medio de la codificación selectiva permitió llegar a la categoría nuclear de la vulnerabilidad programática como categoría explicativa de la ocurrencia de los problemas éticos en la atención primaria.

Palabras clave ética; salud pública; atención primaria de salud; vulnerabilidad social; teoría fundamentada.

\section{Notas}

${ }^{1}$ Universidade do Vale do Rio dos Sinos, Programa de Pós-Graduação em Saúde Coletiva, São Leopoldo, Rio Grande do Sul, Brasil.

$<$ roquejunges@hotmail.com>

Correspondência: Universidade do Vale do Rio dos Sinos, Programa de Pós-Graduação em Saúde Coletiva, Av. Unisinos, 950, Cristo Rei, CEP 93022-000, São Leopoldo, Rio Grande do Sul, Brasil.

${ }^{2}$ Universidade do Vale do Rio dos Sinos, Programa de Pós-Graduação/Mestrado Profissional em Enfermagem, São Leopoldo, Rio Grande do Sul, Brasil.

<barbiani@unisinos.br>

${ }^{3}$ Universidade de São Paulo, Departamento de Enfermagem em Saúde Coletiva, São Paulo, SP, Brasil.

<elma@usp.br> 


\section{Referências}

AYRES, José R. C. M. et al. O conceito de vulnerabilidade e as práticas de saúde: novas perspectivas e desafios. In: CZERESNIA, Dina; FREITAS, Carlos M. (orgs.). Promoção da saúde: conceitos, reflexões e tendências. Rio de Janeiro: Editora Fiocruz, 2003. p. 117-139.

BEAUCHAMP, Tom L.; CHILDRESS, James F. Principles of biomedical ethics. Fifth Edition. New York: Oxford University Press, 2001.

BRASIL. Ministério da Saúde. Política Nacional de Educação Permanente em Saúde. Brasília: Ministério da Saúde, 2009. Disponível em: $<$ http://bvsms.saude.gov.br/bvs/publicacoes/pacto_saude_volume9.pdf >. Acesso em: maio 2018.

CHARMAZ, Kathy. A construção da Teoria Fundamentada: guia prático para a análise qualitativa. Porto Alegre: Artmed/Bookman, 2009.

CRIBB, Alan. Why ethics? What kind of ethics for public health? In: PECKHAM, Stephen; HANN, Alison (eds.). Public health ethics and practice. Bristol: Policy Press, 2010. p. 17-31.

GARRAFA, Volnei; PORTO, Dora. Bioética, poder e injustiça: por uma bioética de intervenção. In: GARRAFA, Volnei; PESSINI, Leocir (orgs.). Bioética, poder e injustiça. São Paulo: Loyola/Centro Universitário São Camilo/SBB, 2003. p. 35-44.

HOLLAND, Stephen. Public health ethics: what it is and how to do it. In: PECKHAM, Stephen; HANN, Alison (eds.). Public health ethics and practice. Bristol: Policy Press, 2010. p. 33-48.
KOTTOW, Miguel. The vulnerable and the susceptible. Bioethics, Edinburgh, v. 17, n. 5-6, p. 460-471, 2003.

KOTTOW, Miguel. Vulnerability: what kind of principle is it? Medicine Health Care Philosophy, Rotterdam, v. 7, n. 3, p. 281-287, 2004.

O'NEILL, Onora. Public health or clinical ethics: thinking beyond borders. Ethics \& International Affairs, Cambridge (Ms), v. 16, n. 2, p. 35-45, 2002.

SCHRAMM, Roland F. A bioética de proteção em saúde pública. In: FORTES, Paulo A.; ZOBOLI, Elma L. C. P. (orgs.). Bioética e saúde pública. São Paulo: Loyola, 2003. p. 71-84.

SCHRAMM, Roland F. Bioética sem universalidade? Justificação de uma bioética latino-americana e caribenha de proteção. In: GARRAFA, Volnei; KOTTOW, Miguel; SAADA, Alya (orgs.). Bases conceituais da bioética: enfoque latino-americano. São Paulo: Gaia, 2006. p. 143-157.

STRAUSS, Anselm; CORBIN, Juliet. Pesquisa qualitativa: técnicas e procedimentos para o desenvolvimento de Teoria Fundamentada. Porto Alegre: Artmed/Bookman, 2008.

UPSHUR, Ross E. G. Principles for the justification of public health intervention. Canadian Journal of Public Health/Revue Canadienne de Santé Publique, Montréal, v. 93, n. 2, p. 101-103, 2002.

Recebido em 22/07/2017. Aprovado em 20/12/2017. 